\title{
Apresentar o Brasil aos brasileiros, aproximar os brasileiros de sua pátria: a materialidade na geografia escolar de Delgado de Carvalho

\author{
Presenting Brazil to Brazilians, enabling \\ Delgado de Carvalho's Geography
} them to come closer to their nation: materiality in
}

Patrícia Coelho Costa

Como exemplo do que serão os programmas do futuro, apesar de muito senões, apesar de lacunas, parece-nos que os progammas de Geographia do Collegio Pedro II representam um novo typo do maximo a exigir em um mínimo de pontos. Os professores Fernando

Raja Gabaglia e Honório Silvestre não recuaram diante de uma inovação radical e assumiram, pode-se dizer, uma attitude peremptória diante da opinião publica pedagógica. Não esboçaram timidamente um gesto no sentido dos methodos modernos, fizeram tabula rasa e construíram um novo edifício, consultando o que havia de melhor, à luz dos interesses da educação nacional (Carvalho, 1925: 23) ${ }^{1}$

Patrícia Coelho é doutoranda em Educação da Universidade de São Paulo (USP) e bolsista da Fundação de Amparo à Pesquisa do Estado de São Paulo (FAPESP), São Paulo, Brasil (pacoel@bol.com.br). Artigo recebido em 27 de junho de 2011 e aprovado para publicação em 27 de setembro de 2011 . 
Em 1923, os programas de Geografia do Colégio Pedro II passaram por grande reformulação. Fernando Raja Gabaglia, coordenador desse processo de mudança, utilizou como base teórica a Geographia do Brasil, obra de perspectiva inovadora, dirigida ao ensino secundário, elaborada por Carlos Delgado de Carvalho, publicada em 1913.

Intelectual de formação francesa, ${ }^{2}$ chegou ao Brasil em 1906. Crítico dos métodos de ensino e também professor de Inglês do Colégio Pedro II, Delgado de Carvalho desempenhou importante papel como educador em seu tempo. Publicou 49 livros $^{3}$ - em sua maioria, manuais escolares, nas áreas de Geografia, História e Sociologia - que contribuíram não só para divulgar conhecimento inédito no país, como para a institucionalização dessas disciplinas como campos autônomos do conhecimento. Participou de movimentos pela melhoria do nosso sistema educacional, sendo um dos signatários do Manifesto dos Pioneiros da Educação Nova. Para ele, a geografia escolar era um importante recurso para construção de nossa nacionalidade, desde que tivesse seus programas transformados:

a geographia do passado foi secca e sem interesse; foi disciplina de pura memória. Que seja dado à nova geração de mestres brasileiros tornal-a mais atrahente, mais practica e mais verdadeira também, fazendo della uma disciplina de bom senso, de intelligencia e patriotismo esclarecido (Carvalho, 1925: 93).

Sendo assim, a perspectiva adotada no Colégio Pedro II não só estudava o Brasil por regiões naturais e não administrativas, como tradicionalmente se fazia, como também sugeria, além do livro, novos materiais didáticos - mapas, gráficos, fotografias, globos e projeções -, arrumados em um ambiente propício ao estudo sobre o Brasil. A sala de aula deveria ser um cenário que ajudaria aproximar o aluno do país que ele não conhecia, reduzindo distâncias, estudando não só os pontos geográficos, mas o homem que lá vivia e sua influência sobre o meio.

O objetivo deste artigo é o de analisar os espaços pedagógicos sugeridos por Carlos Delgado de Carvalho para o ensino da Geografia como uma inovação, que contribuiu não só para a institucionalização dessa disciplina como um campo autônomo do conhecimento, mas também para construir a nossa nacionalidade, à medida que divulgava um conhecimento sobre o país ainda pouco explorado.

Fundamentando a análise nos estudos de Escolano (1998) sobre arquitetura escolar, pretende-se examinar a sala de aula como um ambiente privilegiado para a realização desse programa. Para o autor, através desta é possível identificar 


\section{Apresentar o Brasil aos brasileiros, aproximar os brasileiros de sua pátria}

determinados discursos pedagógicos disseminados no passado. Através dos diferentes símbolos estéticos, é possível refletir sobre as inovações didáticas propostas por Delgado de Carvalho.

Os objetos escolares selecionados por Delgado de Carvalho para compor a sala de Geografia serão outro foco desta análise. Como nos lembra Hernandez Diaz (2002), os objetos escolares fazem parte de um complexo labirinto de relações que nos levam a compreender não só a maneira como se transmitem os conteúdos, mas os valores e as formas de vida de uma sociedade. Partindo da perspectiva etnográfica deste autor, é possível que os objetos nos falem tanto de seu tempo, assim como os discursos. Para isso, é necessário que os interroguemos: de que forma a arquitetura colaborava para a realização do seu método de ensino geográfico? Como esta contribuiu para a construção dessa disciplina como um campo de conhecimento autônomo? Até que ponto a utilização de objetos escolares no ensino da Geografia era uma prática inovadora? Essas são algumas questões que irão nortear este estudo.

Sem dúvida, as investigações etnográficas muito contribuem para os estudos sobre a história da educação brasileira. No entanto, para os historiadores da educação esse tipo de análise ainda representa um grande desafio. A pouca preservação da memória de nossa escolarização é a principal barreira à prática da etnografia neste campo de pesquisa. Em seus estudos, Vidal (2005) alerta que os critérios utilizados nos arquivos escolares nem sempre são os mais adequados. Em geral, como nos lembra Bonato (2005), nesse tipo de acervo os documentos oficiais, como o Diário Oficial, são preservados, ao passo que cadernos de alunos, planos de aula, diários de classe, documentação de professores e cartas são os primeiros a serem descartados.

No acervo pessoal e nos centros de memória das instituições em que Carlos Delgado de Carvalho atuou como professor, o Colégio Pedro II e o Instituto de Educação, não é possível localizar os objetos utilizados em suas aulas, tão pouco relatos de outros professores ou outras formas de registro dos sujeitos que vivenciaram estas experiências educacionais. Diante da escassez de fontes que remetam ao contexto em que essa metodologia se desenvolveu, a perspectiva de investigação etnográfica deste artigo encontra limites, pois se ampara apenas nas descrições da sala de aula e dos objetos apresentadas nas obras do mestre.

\section{A disciplina Geografia do Brasil}

A Geografia do Brasil foi instituída como disciplina a partir do Decreto $\mathrm{n}^{\mathrm{o}} 16.782-\mathrm{A}$, de 13 de janeiro de 1925 . Com o objetivo de regulamentar os ensinos primário, secundário e superior, estabeleceu, entre outros aspectos, o regime 
seriado, destinando duas cadeiras para a Geografia: no $1^{\circ}$ ano seria ministrada a Geografia Geral e, no ano seguinte, a Geografia do Brasil, ao longo do curso de seis anos.

Tal regulamentação não significa necessariamente que os conhecimentos de Geografia do Brasil não eram transmitidos em nossas escolas. Ao estudar a formação das disciplinas escolares, Julia (2002) nos alerta para um erro muito comum nas análises históricas que é associar a transmissão de um tipo de conhecimento à implantação de uma disciplina com seu nome. Muitas vezes, ainda que os programas escolares não possuam oficialmente tal denominação, o conteúdo desta pode estar diluído em outras disciplinas. Assim, o autor nos sugere outras fontes além dos textos normativos, em geral, mais consultados, por estarem em melhores condições de conservação: os manuais, prefácios e cadernos escolares.

Desde o século XIX, os conhecimentos geográficos sobre o nosso país são transmitidos em nossas escolas. Ainda que não houvesse uma disciplina criada especificamente para isso, tanto os volumosos compêndios - como a Chorographia do Brasil, de Mário Veiga Cabral, clássico editorial publicado em 1916, com mais de 600 páginas -, quanto a menos volumosa Geographia do Brasil, obra elaborada pelo próprio Delgado de Carvalho em 1913, com mais de 200 páginas, expõem a preocupação em apresentar o Brasil ao Brasil. Em uma missão nacionalista, era preciso divulgar o conhecimento sobre o país: 4 "O ensino da geographia pátria é entretanto um dever de intelligencia e de patriotismo. Aos nossos jovens patrícios não devemos apresentar a Geographia do Brasil como uma disciplina austera e ingrata ao estudo" (Carvalho 1913: 6). A criação do Instituto Histórico e Geográfico Brasileiro(IHGB), em 1838, também reflete tal preocupação. A disciplina se utilizava desse conhecimento desenvolvido por militares e diplomatas que, em suas viagens, aproveitavam para descrever um Brasil pouco conhecido da maioria: a diversidade cultural, os campos, as cidades e a nossa natureza.

Os estudos de Lima \& Sá (2008) destacam que, durante a Primeira República, vários estudiosos brasileiros debatiam a fragmentação política e a falta de sentimento de identidade nacional. Na década de 1910, as viagens proporcionadas pela Inspetoria de Obras Contras as Secas e pelo Instituto Oswaldo Cruz, com o objetivo de realizar levantamentos das condições sanitárias e socioeconômicas das regiões cruzadas pelo rio São Francisco e de outras áreas do Nordeste e do Centro-Oeste, serviram para reforçar a imagem de ausência de uma nação. Dessas expedições participaram intelectuais como Edgar Roquette-Pinto, Belisário Penna, Arthur Neiva e Delgado de Carvalho, ${ }^{5}$ que, ao entrarem em contato com a realidade de regiões distantes e isoladas, até então desconhecidas, passaram a compartilhar do diagnóstico que o país se constituía de províncias pouco integradas, transformadas em estados pela Constituição republicana de 1891. Ao olhar desses estu- 


\section{Apresentar o Brasil aos brasileiros, aproximar os brasileiros de sua pátria}

diosos, a construção da nação só seria possível à medida que o Estado reconhecesse as necessidades do que se convencionou chamar de Brasil real, e a partir daí, promovesse a adequação entre as instituições políticas e o ambiente social.

Tal debate é reforçado nos anos 1920. O Brasil pergunta a si mesmo quem era. Entre os intelectuais, principalmente, há o questionamento do que é ser brasileiro. Após a Primeira Guerra Mundial, como destaca Oliveira (1997), os valores europeus, antes cultuados, são considerados decadentes, a cópia e o mimetismo passam a ser criticados, sendo considerados problemas da nossa identidade.

O papel da educação no processo de construção da nação foi alvo da análise de Hobsbawm (1990). Nesse sentido, o autor destaca a ação política do Estado que, com intuito de padronizar e homogeneizar suas habitantes, investiu no ensino primário como uma forma de transmitir a todos uma herança cultural, construída a partir de tradições que fazem parte da memória nacional. A transmissão desse tipo de conhecimento sobre a nação é capaz de disciplinar os indivíduos a respeito do pertencimento a um mesmo passado, criando assim os elos de uma nação. No Brasil, em particular por suas dimensões continentais, a criação da disciplina Geografia do Brasil, não à toa, ganha especial importância.

A relevância dos ensinos de geografia e história no processo de consolidação do Estado nacional é uma das perspectivas analisadas por Moraes (2005). Este autor destaca que em países de formação colonial, como o Brasil, essas disciplinas foram vistas pela elite como primordiais ao processo de construção ideológica das identidades nacionais. A implantação do sistema de ensino era uma forma de superar as dificuldades que o processo de colonização impusera ao desenvolvimento do sentimento nacional. Entre as barreiras a serem vencidas estavam a falta de possíveis elementos comuns, tais como raça, etnia e língua, e a enorme desigualdade social que fazia com que escravos e libertos não se sentissem partes da mesma comunidade. Os professores de História e Geografia exercem o papel mediador entre o Estado e a população. Em uma interpretação do nosso passado, alguns fatores são eleitos como preponderantes para ser divulgados como a "história oficial". Por outro lado, o território é valorizado como uma conquista, que deve ser preservado por todos. Todos devem passar a admirar os mesmos personagens. A figura do bandeirante é um exemplo. Este é visto como o herói da nossa expansão territorial, o desbravador da natureza, que combateu índios hostis e, que por isso, deve ser reverenciado.

Os mapas passam a ser um recurso essencial para a transmissão da noção de nacionalidade. Anderson (2009) ressalta que a criação do mapa em formato logo possibilitou a reprodução em escala de uma representação da nação. Assim, o desenho do território, com suas fronteiras e acidentes geográficos, passava a 
ilustrar selos oficiais, cabeçalhos, capas de revistas, paredes e, como não podia deixar de ser, manuais e livros escolares. A possibilidade de visualizar o traçado do país por toda parte auxiliava a incutir na imaginação popular a imagem de uma nação. Através da cartografia era possível destacar não só a particularidade de um território, mas uma história que se desejava transmitir.

Mestre de formação francesa, Delgado de Carvalho procurava analisar nossa geografia a partir de escolas francesas e inglesas, utilizando teorias ainda pouco desenvolvidas no Brasil. ${ }^{6}$ Baseado nas ideias de Vidal de La Blache, defendia que o país deveria ser estudado por regiões naturais que não respeitavam a divisão administrativa estabelecida. Tal perspectiva havia transformado o ensino de geografia na Europa do início do século XX. As regiões não deveriam ser isoladas, mas estudadas de acordo com suas características naturais: "O geographo estuda na hydrographia uma das expressões pelas quaes se manifesta uma região; age do mesmo modo para a vegetação, para as habitações e para os habitantes" (Carvalho, 1925: 78).

A geografia ensinada por diletantes era criticada por Delgado de Carvalho, que chama atenção para a falta de formação específica para geógrafos, pois as primeiras faculdades desse curso só surgiriam na década de 1930. Nesse sentido, criticava a forma como esse conhecimento era transmitido em nossas escolas. Baseado no conhecimento descritivo do nosso país, os professores tinham na memorização do compêndio a estratégia básica de suas aulas. Mudar a maneira como se estudava o país a partir dos preceitos teóricos trazidos por ele da Europa era considerado um exercício cívico:

Ora nestas condições, é na região natural, concepção complexa como vimos, que ressaltam e se salientam especialmente as relações entre phenomenos numa área geographica definida. Dahi o seu valor didactico, dahi também a apparente dificuldade que offerece aos que, até agora, se limitaram a nomenclatura e simples descripções, sem jamais cogitar em explicar, em estabelecer relações de casualidade entre phenomenos. Devido a esta grande lacuna, a geographia do passado foi secca e sem interesse; foi disciplina de pura memória. Que seja dado à nova geração de mestres brasileiros tornal-a mais attrahente, mais pratica e mais verdadeira também, fazendo della uma disciplina de bom senso, de intelligencia e de patriotismo esclarecido (Carvalho 1925: 93).

Em sua Geographia do Brasil (1913), sugeria que o país fosse estudado em cinco regiões: Brasil Septentrional, Brasil do Nordeste, Brasil Oriental, Brasil 
Meridional e Brasil Central. Tal divisão, inspirada na proposta pioneira do professor M. Said Ali, representava uma inovação nos métodos de ensino da geografia em nossas escolas. O manual escolar destinado ao ensino secundário teve várias edições, que demonstram não só o desenvolvimento dos estudos do autor sobre o país, como as transformações do campo da Geografia a partir de seu processo de institucionalização ocorrido a partir da década de $1920{ }^{7}$

A cartografia possui grande importância na metodologia de Delgado de Carvalho. Os mapas estão presentes em todos os capítulos da Geographia do Brasil. Com temas variados - economia, relevo, hidrografia e população - são em sua maioria regionais, ilustrando o tema principal do texto. Desta forma, há uma intenção do autor em destacar o regional: dos 41 mapas que o livro possui, em apenas nove o território nacional aparece completo. Os mapas - de tamanho pequeno, poucos são os que ocupam a página inteira - têm a preocupação em auxiliar o leitor a localizar o que está sendo estudado, a fim de que o entendimento não tenha apenas a imaginação como base.

\section{O uso do espaço nas aulas de Delgado de Carvalho}

Um dos principais objetivos do método desenvolvido por Delgado de Carvalho era criar meios de aproximação do estudante com o conteúdo do programa. Na maior parte das vezes, este era muito distante da realidade do aluno, correndo o risco de ser considerado vazio e sem sentido. A descrição como parte de uma análise assume um papel importante em seu método. Em seus estudos, Rocha (1995) associa tal atividade como parte do processo de institucionalização da chamada geografia moderna: "descrever a realidade estudada de forma objetiva, empiricamente comprovada, racionalmente exata, de maneira a inviabilizar dúvidas e contradições” (Rocha, 1995: 55). Delgado de Carvalho sugeria para isso o uso de vários recursos: mapas, globos, fotografias, fitas cinematográficas, cartões-postais, o mobiliário da sala de aula e o pátio da escola.

Na década de 1930, o ensino primário é visto como grande problema. A iniciativa do então diretor-geral de instrução pública, Carneiro Leão, de reformular o ensino da Geografia,- adotando como método os círculos concêntricos, nos quais o conteúdo vai se tornando gradualmente complexo, passando sempre do conhecido ao desconhecido - foi recebida com entusiasmo por Delgado de Carvalho. Esta foi vista como um grande impulso à transformação do nosso ensino, um passo para a construção da nossa nacionalidade: "É o meio pelo qual uma administração póde facilmente amoldar uma geração, orientar um ensino, unifical-o, nacionalizal-o, segundo as necessidades e os interesses do paiz" (Carvalho, 1925: 40). 
A Methodologia do ensino geographico (Introducção aos estudos de Geographia Moderna) manual destinado aos professores do ensino secundário publicada em 1925, fornece-nos importantes pistas para compreender as mudanças na Geografia escolar defendidas por Delgado de Carvalho. A obra é dividida em três partes: os programmas e os estudos, a orientação moderna e os processos didáticos. Já na primeira parte o autor deixa claro que se dirige aos professores e identifica a falta de formação do profissional como uma das causas de atraso do nosso ensino:

O maior adversário da sciencia verdadeira é o meio-scientista, o que sabe as coisas pela metade. Reconhece-se facilmente este typo social meio-informado: elle não perdoa. A todo momento, está prelecionando e qualquer que seja o auditório, elle há de dizer o que sabe e o que não sabe mas pensa saber. É um perigo na escola publica mergulhar pobres innocentes na neblina traiçoeira do saber e faz obra muitas vezes irreparável, porque vicia a mentalidade (Carvalho, 1925:42).

Para atingir tal objetivo, Delgado de Carvalho acreditava ser necessária a elaboração de uma metodologia para a disciplina na qual o espaço tinha um papel privilegiado. Em espaço adequado, os alunos se sentiriam mais motivados, ficariam mais concentrados e conseguiriam se integrar. Tal perspectiva foi compartilhada com outros educadores de seu tempo, como Fernando de Azevedo, Lourenço Filho e Anísio Teixeira, que, ao implantarem mudanças no ensino normal, projetaram no Instituto de Educação "espaços reservados para as novas práticas pedagógicas, que tinham a intenção de modificar a cultura escolar existente" (Coelho, 2006: 338).

Em seus estudos sobre a arquitetura escolar, Escolano (1998) analisa o espaço da escola como uma construção cultural, onde nada é aleatório. A materialidade deste espaço reflete uma série de estímulos, conteúdos e valores que compõem um currículo oculto. Para ele, a arquitetura faz parte do programa de ensino, ainda que silenciosa. Toda vez que o espaço é utilizado de forma didática constrói-se uma íntima relação entre este e o projeto educativo. Ao estudar o uso do recurso arquitetônico em um método, aproximamo-nos deste e, em relação ao passado, este muitas vezes é um dos poucos recursos que nos resta para compreender o seu significado.

Convidado por Carneiro Leão para ministrar treinamento para professores primários, iniciativa inédita no Distrito Federal, Delgado de Carvalho sugeriu uma apropriação diferente do espaço e dos objetos escolares. Com o objetivo de concretizar um conhecimento até então transmitido de forma abstrata, ele recomendou o uso de recursos simples, conhecidos dos professores, mas em outra função. Tais atividades são destinadas ao ensino primário que, dentro de sua 
perspectiva, tinha uma importante função na formação dos futuros cidadãos que construiriam a nossa nacionalidade a partir da compreensão das razões desta. $\mathrm{O}$ papel da professora primária é, assim, destacado:

Para este fim deve ser armado o professor de todos os processos modernos de explanação e demonstração desde o graphico, o diagramma, o cartogramma, o esboço, o corte, a estatística, até á symbolização concreta, artificial, no taboleiro de areia e no pateo, etc. Elle deve saber como se prende a attenção dos meninos, como se fala á sua imaginação, em linguagem geographica. A história e a geographia são disciplinas de nacionalização por excellencia e exigem do mestre, ao lado das qualidades de pedagogo, as de apostolo (Carvalho, 1925: 41-42).

As noções de geografia consideradas fundamentais - como localizar, observar, medir e representar - deveriam ser trabalhadas com simples objetos da sala de aula, muito conhecidos dos professores, mas agora com outra função. A caneta, por exemplo, serviria como instrumento para medir a largura de uma porta ou a distância da criança em relação ao muro. Tal prática deveria ser diária:

Medem-se então livros, carteiras, distâncias, larguras de portas, quartos, altura de meninos, etc. Os romanos mediam por passos completos de $1 \mathrm{~m} 47$, os gregos por meio de passos de $0 \mathrm{~m} 74$... Os passos de creança são menores. Quantos passos do púlpito à porta? Gregos ou romanos?

O valor educativo e pratico das medições repetidas e frequentes não pode ser exaggerado. É um excellente preparo geographico o das avaliações, quando a medição não é fácil, de alturas, distancias, tamanhos relativos, e o professor deve multiplical-as (Carvalho 1925: 55-56).

Outro artefato que deveria ser utilizado da sala de aula era a mesa, em substituição ao quadro-negro. Delgado de Carvalho salienta que, para entender a proporção utilizada nos mapas, era necessário que se aplicasse o exercício de reprodução de plantas. Utilizando o papel quadriculado sobre a mesa ao invés do quadro-negro, a criança compreenderia com muito mais facilidade. Em seguida, ele sugere que se faça a planta das carteiras da sala de aula, da própria sala e, por fim, do prédio escolar.

O pátio da escola também foi considerado um recurso didático. Visto como um rico lugar de aprendizagem, na falta de outros recursos, o pátio seria ca- 


\section{Patrícia Coelho Costa}

paz de criar imagens que pudessem auxiliar a criança. Assim, ele apresenta como sugestão de atividade:

O pateo da escola, num dia de chuva, vale a pena ser observado: reúnem-se ahi, em miniatura, todas as feições características da crosta terrestre. $\mathrm{O}$ mestre que chame attenção das creanças em primeiro logar sobre a água que corre, procurando sempre os pontos mais baixos; é líquida, isto é, não tem fórma, própria, amolda-se ao recepiente occasional, quando não há pontos mais baixos, ella não corre; fórma poças. Quando corre é sempre na mesma direcção, evitando os obstáculos que estão mais altos. Assim se formam os córregos, os arroios, que se unem para formar os rios, etc etc (Carvalho, 1925: 60-61).

\section{Os gabinetes de Geografia}

Muitas ideias divulgadas por Delgado de Carvalho estavam presentes nos objetivos estabelecidos na reforma do ensino secundário. Instituída por Francisco Campos, em 1930, seu objetivo era adequar o ensino à fase de desenvolvimento mental do aluno, tornando-a prática através da obrigação do professor em dar exemplos brasileiros dos fenômenos estudados e da presença dos vários ramos dessa ciência. Além da parte física e da nomenclatura já tradicionais, deveriam estar distribuídos nos conteúdos previstos a geografia regional e a geografia humana, amplamente divulgadas por esse defensor de Vidal de La Blache.

Muitos defensores do movimento da Escola Nova tinham grande admiração pelo trabalho de Delgado de Carvalho, sendo sua metodologia adotada no Instituto de Educação, laboratório de aplicação escolanovista, dirigido por Lourenço Filho. Uma das perspectivas escolanovistas era a construção de escolas com espaços projetados para novas práticas pedagógicas, com a intenção de modificar a cultura escolar existente. Tanto no Colégio Pedro II como no Instituto de Educação foram montadas salas-ambiente de Geografia.

Os gabinetes de Geografia planejados por Delgado de Carvalho tinham como objetivo tornar o ensino da disciplina mais prático, seguindo a orientação oficial. Para ele, os alunos não eram estimulados a observar, raciocinar, julgar, e se limitavam a estudar para passar no exame. Em geral, as aulas se baseavam na palavra do mestre, complementada pela leitura do compêndio. Defendia, assim, um clima que aproximasse o aluno do conteúdo dos livros, tornando-o mais real. 


\section{Apresentar o Brasil aos brasileiros, aproximar os brasileiros de sua pátria}

O ideal seria que o aluno visitasse todas as regiões do país, a fim de que conhecesse suas regiões, seus recursos e suas necessidades, pois só assim compreenderia a questão nacional. Na impossibilidade disso, a sala de aula deveria fornecer recursos didáticos que permitissem tal exercício. Nesse aspecto, tal espaço deveria se diferenciar de qualquer outro da escola, começando pela própria denominação: sala-ambiente ou gabinete de geografia. Em sua Introdução metodológica aos estudos sociais (1957), ainda expõe uma explicação para tal denominação, que fora apresentada na década de 1930: a expressão "laboratório de ciências sociais", criada nos Estados Unidos, não era adequada, à medida que as ciências sociais não envolviam experiências ou observações científicas. Já a expressão "ambiente" anunciava algo que, para ele, era fundamental à aprendizagem da Geografia: a decoração.

Dessa forma, os artefatos escolares sugeridos por Delgado de Carvalho também ajudavam na realização dos objetivos do método. Estes objetivos, assim como a arquitetura, fazem parte da cultura material da escola. Por meio da análise desses objetos, é possível compreender a dimensão prática dessa metodologia, uma vez que os "objetos da escola não são neutros, são opções. Os elementos visíveis ou ausentes constroem relações entre todos os agentes criando determinado clima, propício a desenvolver a metodologia" (Diaz, 2002: 226).

Delgado de Carvalho sugeria que deveriam ser selecionados para a sala-ambiente dicionários, enciclopédias, livros de diversos autores e compêndios nacionais e estrangeiros. Com esse material, poderiam ser seguidos os passos fundamentais para a exposição da matéria: análise, discussão, comparação e classificação. A consulta apenas do compêndio deveria ser superada. Desde cedo, o aluno deveria ser estimulado a consultar diversas fontes e se acostumar à diversidade das informações. Uma atividade considerada muito importante a ser desenvolvida regularmente seria o preparo de bibliografias: aproveitando as recomendações de leitura que os livros continham, os alunos organizariam fichas com tais informações, que serviriam para consultas futuras. Nesse aspecto, o mobiliário deveria ser planejado para atender às necessidades de consulta. As estantes deveriam ser baixas, de forma a facilitar o acesso aos livros.

O mapa era considerado importante recurso para o ensino da Geografia. Deveria, para isso, ser exato, expressivo (estar de acordo com o que o professor desejasse representar) e inteligível, oferecendo uma visão clara dos fatos geográficos. Sendo assim, deveriam estar espalhados pela sala em murais que pudessem ser visualizados por todos. Na falta de espaço, seriam guardados em local que facilitasse a consulta. Ainda havia a sugestão da mapoteca, armário retangular com várias divisões, que, além de guardar os mapas, teria um suporte para sua exposição. O gabinete deveria contar, ao menos, com os seguintes mapas do Brasil: regiões naturais, físico, político, econômico, histórico e mudo, com litoral bem detalhado. 
A mapoteca (Zarur, 1941:519).

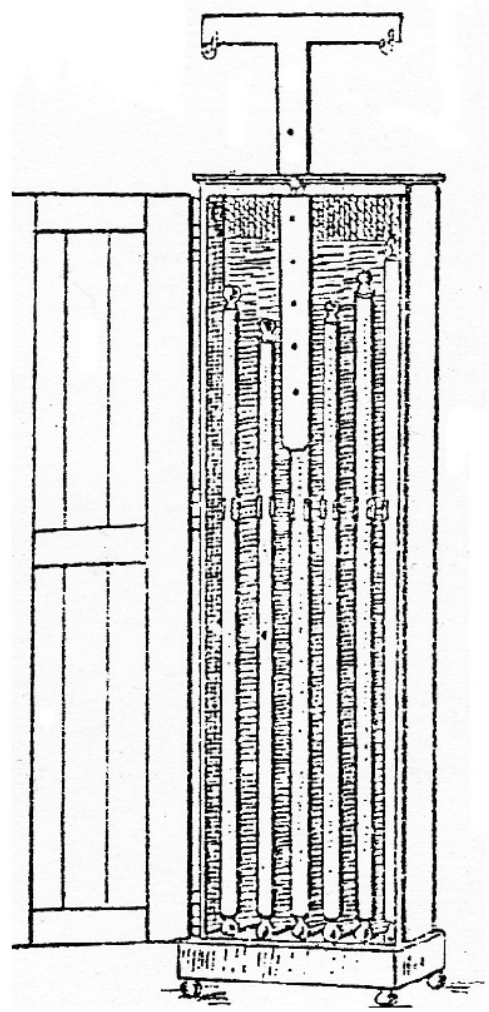

O trabalho de cartografia era considerado muito importante por Delgado de Carvalho, não como forma de decorar pontos geográficos, prática muito difundida em seu tempo, mas como forma de analisar geograficamente as regiões. Para tal atividade, a sala deveria ter mesas amplas, para que o aluno dispusesse de régua graduada, lápis preto, lápis de cor, pois

[o] cartograma representa essencialmente um mapa geográfico esquemático, em que são registradas umas tantas particularidades, geralmente comprovadas por estatísticas. A escolha dos sinais, côres ou traçados convencionais é um problema delicado, do qual depende a clareza, a exatidão e mesmo o atrativo do desenho (Carvalho, 1957: 249). 


\section{Apresentar o Brasil aos brasileiros, aproximar os brasileiros de sua pátria}

Inspirada nos campos de aviação, como relata Zarur(1941), a disposição das mesas em semicírculos, como em um anfiteatro, rompia com as fileiras tradicionais. Isso permitiria a observação de todos os materiais, dispostos de qualquer local da sala: mapas, material de astronomia, mostruário, espécimes geográficos e planisférios em relevo. Além disso, a qualquer momento o professor poderia utilizar o quadro-negro ou o projetor, sem mudar a disposição das carteiras. Tal disposição das carteiras também facilitaria a observação do globo terrestre, que deveria estar suspenso e iluminado, mas ao alcance dos alunos. Sempre que solicitado, o professor deveria colocá-lo ao contato das mãos dos estudantes, pois "há no adolescente o prazer singular de fazer girar o globo imaginando que tem nas mãos uma miniatura do mundo..." (Zarur, 1941: 520).

A fotografia era outro recurso muito valorizado por Delgado de Carvalho. O professor deveria montar, com a colaboração dos alunos, álbuns com fotografias tiradas em excursões. Zarur (1941) destaca que o Colégio Pedro II possuía um gabinete fotográfico, que, além do material de fotografia, contava com uma sala destinada à revelação. O uso desse material tinha uma explicação psicológica: "transmite à mente impressões, as quais, no caso de simples audição ou leitura, tem que depender da imaginação e da memória do aluno" (1941: 522).

A sala deveria ainda dispor de material de meteorologia, como barômetros, termômetros, pluviômetros e anemômetro e de excursão como bússolas. Dessa maneira, poderiam ser feitas experiências com o objetivo de explicar fenômenos geográficos, como a formação do dobramento do relevo e o achatamento dos polos.

Os murais deveriam ser amplos e conter não só mapas, mas também fotos, ilustrações, recortes de jornal, enfim, tudo que atribuísse "impressão de vida, de trabalho em curso e de atividades várias" (Carvalho, 1957: 244). A preocupação de Delgado de Carvalho era de que esse dinamismo se tornasse real.

Os gabinetes de História e Geografia deveriam ser integrados, pois para Delgado de Carvalho, uma ciência não existiria sem a outra, o geógrafo e o historiador se confundiam na mesma pessoa. A relação entre os fatos históricos e os dados geográficos deveria ser estabelecida. Para tal, deveriam ser consultados mapas, dicionários e compêndios das duas disciplinas. Ao tratar das línguas, por exemplo, o professor deveria fazer essa integração:

Deverá geographicamente mostrar sobre o mappa o roteiro seguido pelas prinicipaes línguas, as épocas e directrizes de sua expansão pelos continentes. Deverá também mostrar, por exemplos bem escolhidos, as influencias modificadoras que, no decorrer dos tempos, se exercem sobre uma língua; indicar a influencia do mar, do isolamento, do meio, das ilhas, dos pontos de passagem (Carvalho, 1925: 31). 
Gabinetes de Geografia e História (Zarur, 1941: 524)



\section{Geografia e nacionalismo}

Ao final da década de 1950, ao elaborar sua Introdução metodológica aos Estudos Sociais (1957), Delgado de Carvalho faz um balanço dos empecilhos mais encontrados à realização de sua proposta de sala ambiente, apresentada por ele pela primeira vez ainda na década de 1920: os horários, o tamanho das turmas, os extensos programas. E alerta para uma prática de certos colégios: "acumulam grande riqueza de material que só se acha aí 'para inglês ver', pois é julgado imprudente o professor que dele se quer utilizar em aula. Abundância de material não é sinônimo de ensino eficiente" (Carvalho, 1957: 245). Com tantos anos de luta, não se sente desmotivado:

Mais uma vez, venho tentar a apresentação de novos métodos didáticos para os Estudos Sociais. Solicito novamente a aten- 
ção dos meus colegas que ainda não desanimei em convencer. Reconheço que muitas das minhas ideias são tidas como irrealizáveis, ou pelo menos, prematuras em nosso meio. Não desisto, entretanto, pois algumas são aprovadas por autoridades pedagógicas de primeira grandeza (Carvalho, 1957: s/p).

Durante muito tempo, acreditou-se que as disciplinas escolares eram uma simplificação de um saber desenvolvido nas universidades. Os estudos de História da Educação apontam para o contrário, pois os vários fatores que envolvem a cultura da escola determinaram a especificidade desse tipo de transmissão de conhecimentos. Para compreendermos tal processo, é preciso que nos aproximemos da cultura escolar de um tempo que não vivemos. Nesse sentido, a arquitetura escolar é uma importante fonte, pois tanto a partir da análise dos elementos que a compõem, como pela escolha de determinados objetos é possível criar a aproximação necessária para a compreensão da Geografia escolar.

Ao idealizar uma sala-ambiente de Geografia, Delgado de Carvalho nos dá pistas não só do método por ele desenvolvido, mas de outras práticas pedagógicas realizadas em seu tempo, com as quais desejava romper por considerar ultrapassadas e fruto do diletantismo de seus pares. Assim, os elementos sugeridos para compor esse espaço - como dicionários, livros, material para realização de experiências, mapas e murais - têm a intenção de superar o ensino baseado na memorização e no verbalismo. Velhos conhecidos dos professores, esses materiais sofrem uma apropriação diferente no método de Delgado de Carvalho, que representa a inovação.

O processo de construção da nacionalidade era uma preocupação dos intelectuais brasileiros no início do século XX. Nos amplos debates sobre o assunto, Delgado de Carvalho defendia que o ensino da Geografia deveria ser reformulado, pois, assim, se constituiria em uma arma ainda mais poderosa no desenvolvimento do sentimento de nação. Neste sentido, o ambiente idealizado para Geografia na escola, que adaptava a arquitetura das antigas salas de aula, representa mais uma contribuição deste mestre para a institucionalização da Geografia como disciplina autônoma, à medida que desenvolve práticas específicas. Tal tarefa foi por ele encarada como uma missão cívica, uma vez que era preciso aproximar os brasileiros de sua pátria, ainda desconhecida pela maioria. 
1. Ao longo do texto foi respeitada a grafia original em todas as citações do autor que obedece a regras ortográficas diferentes das que são hoje vigentes.

2. Carlos Delgado de Carvalho era brasileiro nascido na França onde seu pai, diplomata do Império, servia à nação. Só conheceu o Brasil aos 23 anos, quando veio estudar o país, tema de sua tese de doutoramento. Ao chegar, sequer sabia falar nossa língua, pois seu pai, com o advento do regime republicano, passou a odiar o Brasil e desejava romper todas as ligações com a pátria.

3. Ao longo da pesquisa para minha dissertação de mestrado, intitulada $A$ voz do mestre: a trajetória intelectual de Delgado de Carvalho, cataloguei 49 obras: Le Bresil Meridional: sur les étas du sud São Paulo, Paraná et Rio Grande do Sul (1910), Geographia do Brasil (1913), Méterologie du Brésil (1916), Esboço histórico da origem e formação da língua ingleza (1920), Geographia econômica da América do Sul (1921), Fisiografia do Brasil (1922), Methodologia do Ensino Geographico (1925), Chorographia do Districto Federal (1926), História da cidade do Rio de Faneiro de acordo com os programas das escolas públicas municipais (1926), Atlas histórico com Manoel Maurício de Albuquerque (1927), Introdução a Geographia política (1929), Geographia regional do Brasil para quarta série (1930), Sociologia (1930), Sociologia educacional (1933), Sociologia e educação (1934), Sociologia aplicada (1934), Sociologia experimental (1934), Geographia humana e política e econômica (1934), Os continentes e as principaes potencias. Exercícios práticos de cartographia esquemática (1934), Geographia humana e política (1935), História Geral (1935), Práticas de Sociologia (1938), Geografia elementar (1940), O canto das sereias (1940), Noções de economia e esta- tística (1941), Geografia Geral e do Brasil (4 séries) (1943), Geografia física e humana para a la ser (1943), Geografia regional do Brasil (1943), Geografia física e humana do Brasil (1943), Geografia dos continentes (1944), Súmulas de História colegial (1947), Didática das Ciências Sociais (1949), Geografia física e humana do Brasil (1949), História geral e do Brasil (4 séries) (1949), Textos de Sociologia educacional (1951), Aspectos geográficos da terra bandeirante (1954), História geral: compêndio de informação para uso de docentes (1956), Introdução metodológica aos Estudos Sociais (1957), História diplomática do Brasil (1958), História Geral-Idade Média (1959), História geral contemporânea (1960), África - geografia política (1960), Atlas das Relações Internacionais (1960), Geografia Humana (1963), OSPB (1967), Relações internacionais (1971), História das Américas (1975) História documental (Moderna e Contemporânea) (1976). Com objetivo de traçar a trajetória intelectual do autor, considerei o caráter inovador dessas obras para o universo intelectual brasileiro do início do século XX. Partindo da perspectiva de Bourdieu, classifiquei sua produção até a década de 1930 como estratégia de subversão, uma vez que o intelectual rompe com as regras reconhecidas como legítimas pelo campo, buscando seu reconhecimento como autoridade científica.

4. Vlach (1989) destaca a importância dada por Delgado de Carvalho às disciplinas de História e Geografia, por ele consideradas as disciplinas de nacionalização por excelência. Tal consciência é, para a autora, uma demonstração do quanto este intelectual acreditava no potencial político dessas disciplinas e o quanto mereciam atenção em nossas escolas. Afinal, na década de 1920 a construção do Estado nacional ainda era uma preocupação. 


\section{Apresentar o Brasil aos brasileiros, aproximar os brasileiros de sua pátria}

5. No caso de Delgado de Carvalho, essas viagens foram de grande importância para a elaboração da Geographia do Brasil (1913).

6. Machado (2000) destaca, em seus estudos, que na primeira década do século XX tais teorias circulavam em mão única, pois existiam apenas escolas de medicina, direito e engenharia.

\section{Referências bibliográficas}

ANDERSON, Benedict. Comunidades imaginadas. Reflexões sobre a origem e a difusão do nacionalismo. São Paulo: Companhia das Letras, 2008.

BONATO, Nailda da Costa. Os arquivos escolares como fonte para a história da educação. Revista Brasileira de História da Educação, $\mathrm{n}^{\circ}$ 10, jul/dez 2005, p.193-220.

COELHO, Patrícia. $A$ voz do mestre: a trajetória intelectual de Carlos Delgado de Carvalho. Dissertação (Mestrado em Educação. Universidade do Estado do Rio de Janeiro, Rio de Janeiro, 2007.

Viajando pelo mundo através do caderno de cartografia: uma proposta pedagógica de Carlos Delgado de Carvalho. In: Vozes da educação: memórias e história das escolas de São Gonçalo. São Gonçalo, 2007.

CARVALHO, Carlos Delgado de. Methodologia do ensino geographico (introducção aos estudos de Geographia Moderna). Rio de Janeiro: Francisco Alves, 1925.

Introdução à geographia política. Rio de Janeiro: Francisco Alves, 1929.

Introdução metodológica aos estudos sociais. São Paulo: Agir, 1957.
7. A primeira edição dessa obra possui 250 páginas e apresenta as principais características da hidrografia, do relevo e da climatologia das regiões. Não houve nessa edição um capítulo dedicado a cada uma delas. Ainda que tal trabalho, denominado de "Synthese geographica", fosse anunciado na introdução para breve, isso só ocorreria na terceira edição, publicada em 1927.

ESCOLANO, Augustin. Arquitetura como progresso. Espaço-escola e currículo. In: FRAGO, Antonio Vinao \& ESCOLANO, Augustin (orgs.). Currículo, espaço e subjetividade - a arquitetura como programa. Rio de Janeiro: DP\&A, 1998, p. 9-57.

DIAZ, Jose Maria Hernandez. Etnografía y historia material de la escuela. In: ESCOLANO, Augustin \& DIAZ, Jose Maria Hernandez. La memória y el deseo cultura de la escuela y educacion deseada (coords.) $1^{\mathrm{a}} \mathrm{ed}$. Valencia, Tirant la blanch, 2002, p. 225-246.

HOBSBAWM, Eric. Nações e nacionalismo desde 1780: programa, mito e realidade. Rio de Janeiro: Paz e Terra, 1990.

JULIA, Dominique. Disciplinas escolares, objetivos e apropriação. In: LOPES, Alice Casemiro \& MACEDO, Elizabeth (orgs.). Disciplinas e integração curricular história e política. Rio de Janeiro: DP\&A, 2002, p. 37-71.

LIMA, Nísia Trindade \& SÁ, Dominich Miranda. Roquette-Pinto e sua geração na república das letras e da ciência. In: LIMA, Nísia Trindade \& SÁ Dominich Miranda (orgs.). Antropologia Brasiliana: ciência e educação na obra de Roquette-Pinto. Belo Ho- 
rizonte: Editora UFMG; Rio de Janeiro: Editora Fiocruz, 2008, p. 57-85.

MACHADO, Lia Osório. As ideias no lugar: o desenvolvimento do pensamento geográfico no Brasil do início do século XX. Terra Brasilis, n. 2, jan/jun 2000, p. 11-31.

MORAES, Antonio Carlos Robert. Território e história no Brasil. São Paulo: Annablume, 2005.

OLIVEIRA, Lucia Lippi. Questão nacional na Primeira República. In: CARVALHO, Helena \& COSTA,Wilma Peres da (orgs.). A década de 1920 e as origens do Brasil moderno. São Paulo: Editora da UNESP, 1997, p. 185-194.

ROCHA, Genílton O. R. A trajetória da disciplina geografia no currículo escolar brasileiro (1838-1942). Dissertação (Mestrado em Educação), São Paulo, Pontifícia Universidade Católica de São Paulo, 1996.
VIDAL, Diana. Arquivos escolares: desafios à prática e à pesquisa em história da educação. Revista Brasileira de História da Educação $\mathrm{n}^{\mathrm{O}}$ 10, jul/dez 2005, p. 71-74.

VLACH, Vânia Rubia Farias. Carlos Miguel Delgado de Carvalho e a orientação moderna em geografia. In: VESENTINI, José Willian (org.). Geografia e ensino: Textos críticos. Campinas: Papirus, 1989, p. 149160.

ZARUR, Jorge. A geografia no ensino secundário. In: O IBGE e a Educação - $1^{a}$. Conferência Nacional de Educação. Rio de Janeiro: Serviço Gráfico do IBGE, 1941.

ZUSMAN, Perla Brígida \& PEREIRA, Sérgio Nunes. Entre a ciência e a política: um olhar sobre a geografia de Delgado de Carvalho. Terra Brasilis, n. 2, jan/jun 2000, p. 51-78.

\section{Resumo}

Este texto analisa o uso do espaço e de objetos escolares no ensino da Geografia a partir da perspectiva de Carlos Delgado de Carvalho. Para esse mestre, de formação francesa, adepto das teorias de Ratzel, apresentar o Brasil através dessa disciplina era uma missão cívica. Para tal, idealizou gabinetes nos quais recursos científicos foram utilizados para romper com os métodos de ensino de seu tempo, que se baseavam no verbalismo. O estudo dessa arquitetura e de seus objetos, a partir de uma perspectiva etnográfica, revela características da cultura material escolar da década de 1930.

Palavras-chave: Geografia; espaço; objetos escolares; etnografia; cultura material escolar.

\section{Abstract}

This article examines the use of space and school objects for the teaching of Geography, based on Carlos Delgado de Carvalho's perspective. According to this lecturer, who had a French academic background and followed the 
theories developed by Ratzel, it was a civic mission to present Brazil through Geography. With this purpose in mind, he projected chambers where scientific resources were used to promote a rupture with teaching methods adopted by his contemporaries, which were grounded on verbalism. The study of this architecture and its objects, when carried out from an ethnographic perspective, discloses characteristics of the material culture adopted by schools in the 1930's.

Key words: Geography; space; school objects; Ethnography; material culture at school.

\section{Résumé}

Ce texte examine l'usage de l'espace et d'objets scolaires dans l'apprentrissage de la Géographie à partir de la perspective de Carlos Delgado de Carvalho. D'après ce professeur, de formation française et adepte des théories de Ratzel, la présentation du Brésil à travers cette discipline était une mission civique. Pour cela, il a idéalisé des gabinets où des ressources scientifiques étaient utilisées pour rompre avec les méthodes d'apprentissage de son époque, qui étaient fondées sur le verbalisme. L' étude de cette architecture et de ses objets, développée à partir d'une perspective ethnographique, révèle des caractéristiques de la culture matérielle de l'école lors des années 1930.

Mots-clés: Géographie; espace; objets scolaires; ethnographie; culture matérielle de l'école. 